\title{
Major trace elements and their binding proteins in the early phase of Covid-19 infection
}

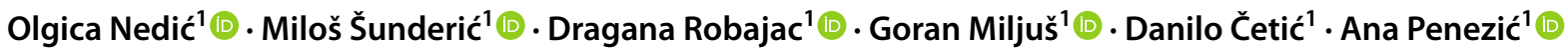

Received: 8 July 2021 / Accepted: 31 January 2022 / Published online: 12 February 2022

(c) The Author(s), under exclusive licence to Society for Biological Inorganic Chemistry (SBIC) 2022

\begin{abstract}
Metal ions seem to play important roles in the pathogenesis of the novel coronavirus disease of 2019 (Covid-19) and are under investigation as potential prognostic markers and supplements in therapeutic procedures. The present study was aimed at assessing the relationship between the most abundant essential microelements (iron, zinc and copper) and their major binding proteins in the circulation in the early stage of infection. The concentration of zinc ions was measured to be higher in infected than in healthy persons, as well as ratios zinc/albumin and zinc/alpha-2-macroglobulin. Increased zinc levels could be attributed to cellular redistribution of zinc ions or to a use of zinc supplementation (zinc concentration was above the upper reference limit in one-third of infected individuals). Immunoblot analysis of protein molecular forms revealed that infected persons had greater amounts of proteinase-bound alpha-2-macroglobulin tetramer and albumin monomer than healthy individuals. The quantities of these forms were correlated with the concentration of zinc ions $(r=0.42$ and 0.55 , respectively) in healthy persons, but correlations were lost in infected individuals, most likely due to very high zinc concentrations in some participants which were not proportionally followed by changes in the distribution of protein species. Although we still have to wait for a firm confirmation of the involvement of zinc in beneficial defense mechanisms in patients with Covid-19, it seems that this ion may contribute to the existence of circulating protein forms which are the most optimal.
\end{abstract}

Olgica Nedić

olgica@inep.co.rs

1 Institute for the Application of Nuclear Energy (INEP), University of Belgrade, Banatska 31b, Zemun, Belgrade, Serbia 


\section{Graphical abstract}
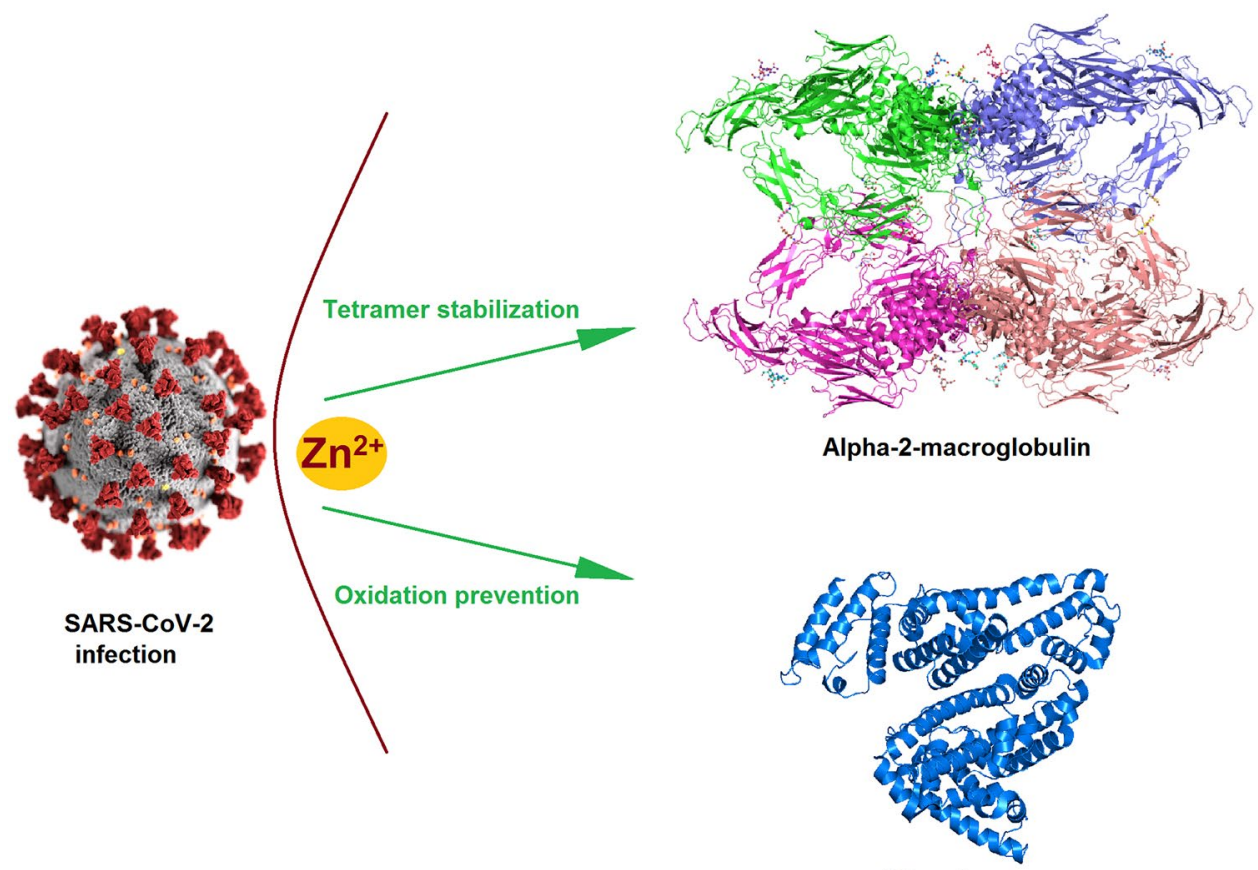

Albumin

Keywords Covid-19 · Alpha-2-macroglobulin $\cdot$ Albumin $\cdot$ Zinc

\author{
Abbreviations \\ Covid-19 Corona virus disease of 2019 \\ IL Interleukin \\ RNA Ribonucleic acid \\ SARS-CoV-2 Severe acute respiratory syndrome corona- \\ virus 2 \\ SDS-PAGE Sodium-dodecyl-sulfate-polyacrylamide \\ electrophoresis
}

\section{Introduction}

The epidemic of the novel coronavirus disease of 2019 (Covid-19) was caused by a severe acute respiratory syndrome coronavirus 2 (SARS-CoV-2) whose primary targets are tissues expressing angiotensin-converting enzyme 2 receptor, including lungs, heart, kidney and endothelium, leading to systemic manifestations [1]. Since December 2019, Covid-19 has spread worldwide and turned into a global pandemic [2]. A number of studies investigated potential roles of metal ions in the pathogenesis of this disease as well as the possibility of the utilization of trace elements in prognostic and therapeutic procedures and protocols [3-5].

Metal ions play vital roles in many physiological processes [6]. Major trace elements in the circulation, such as iron, zinc and copper, are present in similar $\mu \mathrm{M}$ concentrations [7]. Small quantities are present in a free form, whereas the majority is bound to/associated with different biomolecules, mostly proteins [8]. Some proteins express their activity only in the presence of specific metal ion(s), while others serve to transport or store them. All three mentioned metal ions are recognized as essential for the proper function of the immune system, respiration and defense against free radicals. Their deficiency may be associated with more severe infection and inflammation, or dysbalance in the production of cytokines and redox processes.

The most abundant protein whose function depends on iron is hemoglobin, transferrin serves as its transporter and ferritin as its major storage protein in cells. Adequate iron intake is vital for the maintenance of the innate and adaptive immune response, predominantly cell-meditated immunity, since iron status is negatively correlated with levels of proinflammatory cytokines [9-11].

The function of thousands of enzymes, transcription factors and other proteins depends on the presence of zinc ions $[7,12]$. It mediates molecular interactions, acts as a signaling agent and is required to maintain the structure of almost $10 \%$ of body proteins [13, 14]. Albumin and alpha-2-macroglobulin are the principle zinc binding proteins in the circulation. Zinc supplementation in patients with Covid-19 is recommended as higher zinc levels correlate with less severe infection, enhanced interferon type 1 response and lower interleukin 6 
(IL-6) concentration [15]. In vitro studies have shown viral expansion in cells infected with SARS-CoV-2 virus when the concentration of zinc is low [16]. Zinc ions inhibit SARSCoV-2 RNA polymerase and increase the efficiency of therapeutic agents which are zinc ionophores [17]. In some studies, non-surviving patients with Covid-19 were found to have lower concentrations of zinc in serum than survivors [18, 19], but in other, no difference was noted [20].

The presence of copper ions is essential for the function of enzymes involved in an antioxidative defense system. Copper in the circulation is transported bound to albumin, while ceruloplasmin mediates iron transportation inside cells. Sufficient supply of copper in patients with Covid-19 is important for the proliferation of $\mathrm{T}$ helper cells and regulation of cytotoxicity of natural killer cells [5]. Copper ions can inactivate viral nucleic acids, inhibit enzymes vital for viral replication, induce autophagy and apoptosis, and possibly play role in coagulopathy. In a study of Zeng et al. [20], severe cases of Covid-19 were measured to have higher levels of blood copper compared to less severe cases.

Zinc and copper ions are competitively absorbed in the gastro-intestinal tract. Iron and calcium can interfere with their absorption [21]. The ratio of zinc and copper ions is crucial to maintain cellular homeostasis [12], and so is the ratio of albumin and zinc [22]. The copper/zinc ratio is one of the sources and an indicator of the oxidative stress. In some studies, the copper/zinc ratio was reported to be higher than reference in severe Covid-19 patients [23, 24], but in the study of Hackler et al. [25], higher concentrations of copper and ceruloplasmin were measured in the surviving than non-surviving patients. Thus, additional investigations are needed to resolve these inconsistencies.

Given the importance of metal ions for human health, as well as the existence of contradicting data on their status in patients with Covid-19, the present study was aimed at assessing the relationship between the most abundant essential microelements and their major binding proteins in the circulation, and specifically in the early stage of infection. This assessment might assist in early risk stratification and decision on the appropriate therapeutic approach. Serum concentrations of iron, zinc and copper ions, albumin, alpha-2-macroglobulin, transferrin, ceruloplasmin and ferritin, as well as the concentration of hemoglobin in whole blood were determined. Ion/ protein ratios and possible differences in the distribution of protein molecular forms were also investigated.

\section{Materials and methods}

\section{Samples}

Whole blood and serum samples from adult individuals in the early stage of infection with SARS-CoV-2 $(n=60$,
31 males and 29 females, age $51.4 \pm 12.6$ years) were analyzed together with samples from age and gender matched healthy persons $(n=20,9$ males and 11 females, age $54.1 \pm 14.3$ years). Blood samples were collected after overnight fasting in the Institute for the Application of Nuclear Energy (INEP), which is included in the Public Health Service in Serbia. Infected persons without serious disease symptoms came to the laboratory with the intention to assess possible infection by serology testing. The inclusion criteria for the healthy group were: persons denying any health problem, acute or chronic, non-pregnant, whose basic hematological and biochemical parameters were within reference ranges (total white blood cell count, lymphocytes, granulocytes, monocytes, red blood cells, platelets, hemoglobin, hematocrit, $\mathrm{MCHC}, \mathrm{MCH}$, sedimentation, concentrations of glucose, urea, creatinine, bilirubin, cholesterol, triglycerides, electrolytes, total proteins, C-reactive protein, D-dimer and activities of AST, ALT, ALP, LDH). The inclusion criteria for the group of patients were: no pregnancy, the presence of IgM class of anti-SARS-CoV-2 antibodies in serum (above the index of 50, the reference limit being 33), concentrations of C-reactive protein and D-dimer within reference ranges, no previous knowledge of COVID-19 infection, no temperature at the admission to the laboratory (checked in the laboratory). The study conformed with the Helsinki Declaration of 1975 (as revised in 2008). It was approved by the Institutional Review Board (Approval no. 02-286/4) and oral informed consent was obtained from participants regarding the use of their blood leftovers for the research purpose.

\section{Determination of metal ion and protein concentrations}

Iron concentration was measured by ferrozine method, zinc by bromo-PAPS (Biosystems, Spain) and copper by bathocuproine assay (Sigma-Aldrich, USA). Albumin concentration was determined by bromocresol green method (BioSystems, Spain), while other proteins in serum were measured by immunochemical assays: transferrin and ceruloplasmin by immunoturbidimetry (Abbott, USA), ferritin by IRMA (INEP, Serbia) and alpha-2-macroglobulin by immunonephelometry (Siemens, Germany). The concentration of hemoglobin was assessed using hematological analyzer (Orphee Mythic, Switzerland).

\section{Analysis of protein forms by electrophoresis}

Proteins in serum samples were resolved by non-reducing SDS-PAGE (to retain oligomer forms) in a standard manner on $6 \%$ (for the analysis of alpha-2-macroglobulin) or $8 \%$ gels (for albumin, transferrin and ceruloplasmin) and electrotransferred to nitrocellulose membranes. In addition, native electrophoresis was performed for the analysis of 
alpha-2-macroglobulin tetramers, using 5\% gels and commercial native alpha-2-macroglobulin (Bio-Rad, USA) as a protein standard. Serum samples were diluted in $50 \mathrm{mM}$ phosphate buffer saline (PBS) $\mathrm{pH}$ 7.4. Optimal dilution was determined for the analysis of each protein: 1:40 for alpha2-macroglobulin for SDS-PAGE and 1:50 for native electrophoresis, 1:50 for albumin and transferrin, and 1:20 for ceruloplasmin. Each protein transfer on nitrocellulose membrane was checked by Ponceau S staining and the results obtained were consistent with serum dilutions. Samples were assayed in duplicate. Molecular forms were studied by immunoblotting using optimized dilutions of commercial antibody preparations: polyclonal sheep anti-human alpha-2-macroglobulin antibody (AbD Serotec, UK, 1:10,000), polyclonal sheep anti-human transferrin antibody (INEP, Serbia, 1:10,000), monoclonal mouse anti-human albumin (1:500) and ceruloplasmin (1:3000) antibody (Santa Cruz, USA), followed by the appropriate secondary antibody (Vector Laboratories Inc, USA, 1:10,000) and enhanced chemiluminescence substrate (ECL). Intensities of specific protein bands were quantified by ChemiDoc MP imaging system (Bio-Rad Laboratories Inc, USA), while signal detection and analysis were performed using Image Lab v6.1 software (Bio-Rad Laboratories Inc, USA). A set of molecular mass markers for SDS-PAGE was Blue Wide Range Protein Ladder (Cleaver Scientific Ltd, UK, range 10-245 kDa) and for native electrophoresis a mixture of five individual markers provided by SERVA Electrophoresis GmbH (Germany, of 45, 67, 160, 240 and $450 \mathrm{kDa}$ ) plus alpha-2-macroglobulin (Bio-Rad, USA, $720 \mathrm{kDa}$ ) was prepared before electrophoresis.

\section{Statistical analysis}

The normality of the distribution of values was tested using Kolmogorov-Smirnov test, and the obtained results were expressed either as means $\pm \mathrm{SD}$, in the case of concentrations, or medians with 2.5-97.5th interval, in the case of ratios (not Gaussian distribution), and compared between groups using Student $t$ test or Mann-Whitney $U$ test, whereas $p$ values were corrected for multiple testing using False Discovery Rate (FDR) test. Correlations between metal ions and their binding proteins were also investigated. Data were additionally analyzed according to gender and age.

\section{Results}

The results on metal ion and protein concentrations in two groups of individuals exhibited statistically significant differences only in the concentrations of hemoglobin and zinc (Table 1). The measured hemoglobin levels were generally lower in infected than in healthy individuals, and also lower in women than in men. Zinc levels were, however, higher and with three times greater SD in the group of infected persons. The concentration of zinc was close to the lower reference limit in healthy persons and in 20 out of 60 infected persons, it was above the upper reference limit. No difference was detected between males and females regarding zinc concentration in either group of participants and there was no correlation with age. When ratios of specific ions and their binding proteins were examined, significant differences between groups were found only for the ratios zinc/albumin and zinc/alpha-2-macroglobulin (Table 2). No gender difference or correlation with age was recorded.

Relatively strong correlations $(r \geq 0.50)$ were found between concentrations of zinc and albumin $(r=0.50)$ and copper and ceruloplasmin $(r=0.53)$ in healthy individuals, but they were lost in infected subjects. Concentrations of iron and ferritin, however, were strongly correlated only in infected persons $(r=0.64)$.

Table 1 Concentrations of metal ions and binding proteins in the circulation of healthy and SARS-CoV-2-infected individuals (mean \pm SD)

\begin{tabular}{|c|c|c|c|c|c|}
\hline Population group/concentration & Reference values $^{\mathrm{a}}$ & $\begin{array}{l}\text { Healthy individuals } \\
(n=20)\end{array}$ & $\begin{array}{l}\text { Infected individuals } \\
(n=60)\end{array}$ & $\begin{array}{l}\text { Significant dif- } \\
\text { ference } \\
T \text { test } \\
(P \text { value })\end{array}$ & $\begin{array}{l}\text { Significant } \\
\text { difference } \\
\text { FDR test } \\
(P \text { value })\end{array}$ \\
\hline Iron $(\mu \mathrm{M})$ & $9-31$ & $19.0 \pm 7.7$ & $18.2 \pm 6.6$ & - & - \\
\hline $\operatorname{Zinc}(\mu \mathrm{M})$ & $12-18$ & $13.4 \pm 1.6$ & $16.3 \pm 5.0$ & 0.0004 & 0.0029 \\
\hline Copper $(\mu \mathrm{M})$ & $10-22$ & $12.0 \pm 2.0$ & $11.2 \pm 3.7$ & - & - \\
\hline Hemoglobin (g/L) & $110-170$ & $150 \pm 13$ & $136 \pm 15$ & 0.0101 & 0.0327 \\
\hline Transferrin $(\mathrm{g} / \mathrm{L})$ & $1.7-3.8$ & $2.8 \pm 0.3$ & $2.6 \pm 0.5$ & - & - \\
\hline Ferritin $(\mu \mathrm{g} / \mathrm{L})$ & $4-280$ & $85 \pm 75$ & $121 \pm 115$ & - & - \\
\hline Albumin $(\mathrm{g} / \mathrm{L})$ & $35-55$ & $47.0 \pm 3.7$ & $49.1 \pm 4.8$ & - & - \\
\hline Alpha-2-macroglobulin (g/L) & $1.2-2.5$ & $2.1 \pm 0.4$ & $1.9 \pm 0.3$ & - & - \\
\hline Ceruloplasmin $(\mathrm{g} / \mathrm{L})$ & $0.20-0.60$ & $0.35 \pm 0.04$ & $0.33 \pm 0.06$ & - & - \\
\hline
\end{tabular}

${ }^{\text {a }}$ Reference values were taken from the reagent producer manuals 
Table 2 Relative ratios of metal ions and their binding proteins in the circulation of healthy and SARS-CoV-2-infected individuals (median, 2.5-97.5th interval)

\begin{tabular}{lllll}
\hline Population group/relative ratio & $\begin{array}{l}\text { Healthy individuals } \\
(n=20)\end{array}$ & $\begin{array}{l}\text { Infected individuals } \\
(n=60)\end{array}$ & $\begin{array}{l}\text { Significant } \\
\text { difference } \\
T \text { test } \\
(P \text { value })\end{array}$ & $\begin{array}{l}\text { Significant } \\
\text { difference }\end{array}$ \\
$\begin{array}{l}\text { FDR test } \\
(P \text { value })\end{array}$ \\
\hline Zinc/albumin & $0.28(0.22-0.34)$ & $\begin{aligned} 0.33(0.17-0.56) \\
8.7(3.0-13.2)\end{aligned}$ & 0.0156 & 0.0160 \\
Zinc/alpha-2-macroglobulin & $5.3(4.2-7.5)$ & 0.0144 & 0.0160 \\
\hline
\end{tabular}

Since proteins can exist in more than one molecular form (isoforms, dimers, oligomers, complexes), albumin, transferrin, ceruloplasmin and alpha-2-macroglobulin were further investigated by non-reducing SDS-PAGE followed by immunoblotting. Representative results are shown in Fig. 1. Transferrin and ceruloplasmin were detected as one major band, whereas alpha-2-macroglobulin and albumin were detected as several molecular species. The dominant molecular form of alpha-2-macroglobulin was dimer (360 kDa), monomer form $(180 \mathrm{kDa})$ was barely visible and there were several higher molecular forms of varying intensities and proportions. A comparison of the major band intensities between two study groups revealed no significant difference. As for albumin, the relative abundance of dimer compared to monomer forms was greater in healthy than in infected individuals $(P=0.0007)$. Higher molecular forms of alpha-2-macroglobulin and albumin were not compared, as their identity was unknown (oligomers, complexes?). Gender and age were not found to influence molecular distribution.

Since alpha-2-macroglobulin can bind proteinases forming complexes with an increased electrophoretic mobility compared to native tetramer $[26,27]$, the relative presence of two types of tetramers (the so-called "slow" and "fast") was investigated by native electrophoresis and immunoblotting. Representative results are shown in Fig. 2. The ratio between "slow" and "fast" forms was calculated for both groups of samples. Statistical analysis revealed that the ratio, expressed as $\mathrm{Me}$ (2.5-97.5th interval), was $4.8(3.0-9.5)$ in healthy persons and $2.9(1.4-7.6)$ in infected individuals, indicating a significant increase of the "fast" tetramer due to infection $(P=0.0091)$. The ratio was lower in women than in men in the infected group $(P=0.0497)$, without correlation with age.

When the distribution of molecular forms and the concentration of zinc were compared, a strong correlation was found in the case of albumin $(r=0.55)$ and moderate in the case of alpha-2-macroglobulin $(r=0.42)$ in healthy individuals. However, correlations were lost in the group of infected persons, most likely due to very high zinc concentrations in some participants which were not proportionally followed by changes in the distribution of protein molecular species.

\section{Discussion}

Persons in the early stage of Covid-19 infection included in this study exhibited similar status in respect to iron, copper and their major binding proteins in the circulation as healthy individuals, except for hemoglobin whose levels were found to be lower, but still within reference limits. In addition, concentrations of iron and ferritin were strongly correlated only in infected persons. Sonnweber et al. [28] have reported that severity of Covid-19 disease was accompanied by increased levels of serum ferritin and soluble transferrin receptor, whereas the concentration of hemoglobin remained unaltered. According to Biamonte et al. [29], the ratio of iron and ferritin seems to have a potential to segregate Covid-19 survivors and non-survivors.

An increased concentration of zinc and altered ratios of zinc and its binding proteins were found in infected persons. This change could be attributed to cellular redistribution of zinc ions or to a prophylactic use of zinc supplementation. As already mentioned in Introduction, some reports connect zinc levels with the survival rate, but others deny the relation. There is still no strong evidence that zinc administration is beneficial in the prevention and treatment of Covid-19 patients [17, 30] and zinc supplementation trials did not confirm the correlation between serum zinc concentration and its intake [22].

When protein molecular forms were examined, it was found that infected persons had similar relative abundance of alpha-2-macroglobulin dimer, as a dominant species after SDS-PAGE. On the other hand, the relative ratio of the native and proteinase-bound tetramers was lower in the infected individuals, as assesses by native electrophoresis. Thus, the portion of tetramers in complex with proteinases was greater in infected persons, which can be possibly explained by an increased presence of proteinases whose synthesis and release is elevated at the onset of infection.

Alpha-2-macroglobulin is a universal proteinase inhibitor and a mediator of the innate immune response [31]. It is homotetramer with molecular mass of $720 \mathrm{kDa}$. Two monomer units are connected covalently into dimers which are assembled into tetramer via disulphide bonds forming a so-called bait region responsible for covalent 


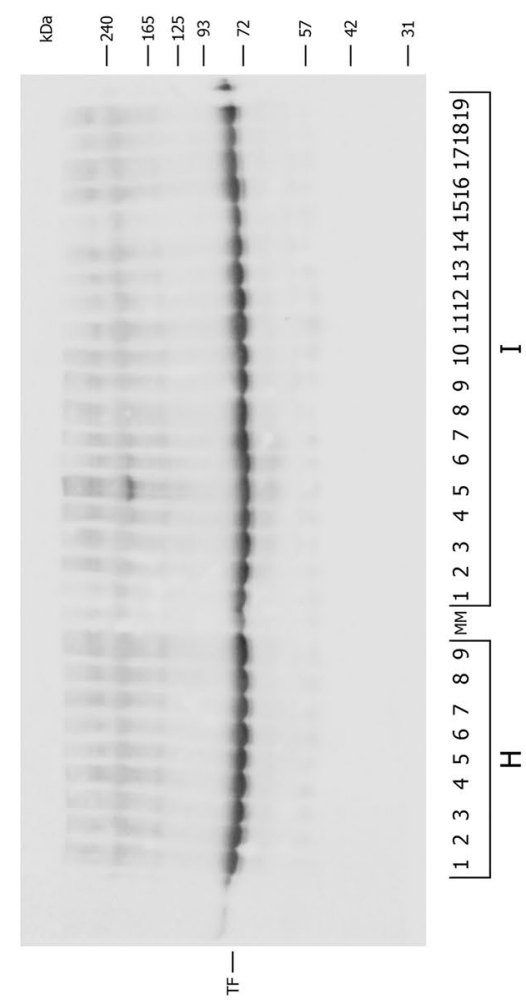

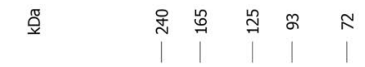

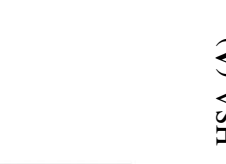

定

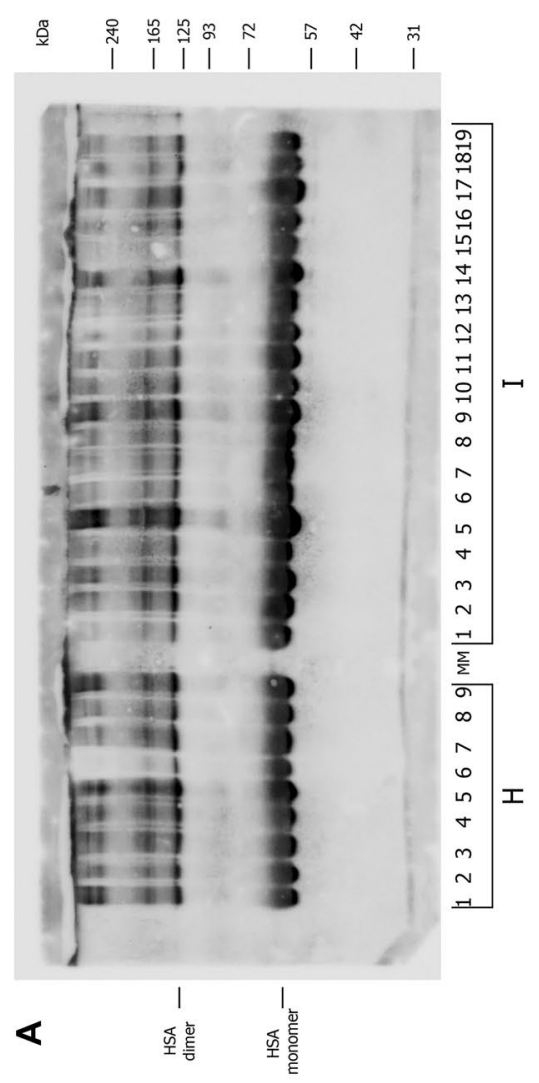

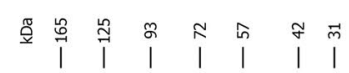

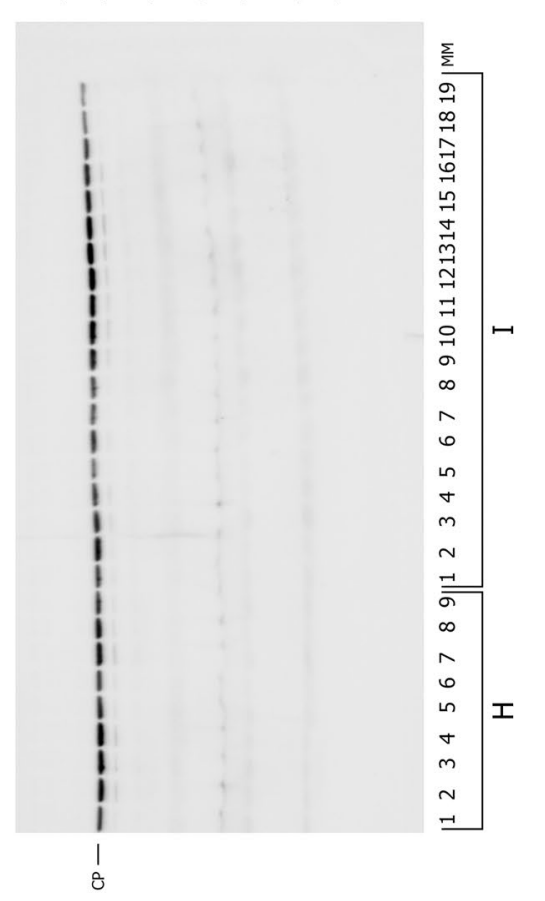

$\mathcal{U}$

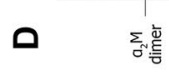

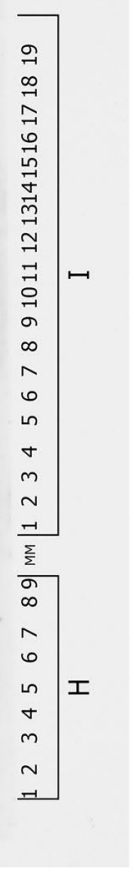

音

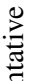

范



$\pm$

:

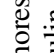

응

氮:

ฮ

卷

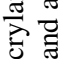

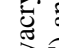

त्

命

离

옥을

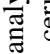

흥

늘

志

ㅎํำ 
Fig. 2 Immunoblot analysis of alpha-2-macroglobulin $(\alpha 2 \mathrm{M})$ after native electrophoresis of the representative samples ( $H$-healthy, $I$-infected individuals); $\mathrm{ST}$ is the commercial native $\alpha 2 \mathrm{M}$ standard

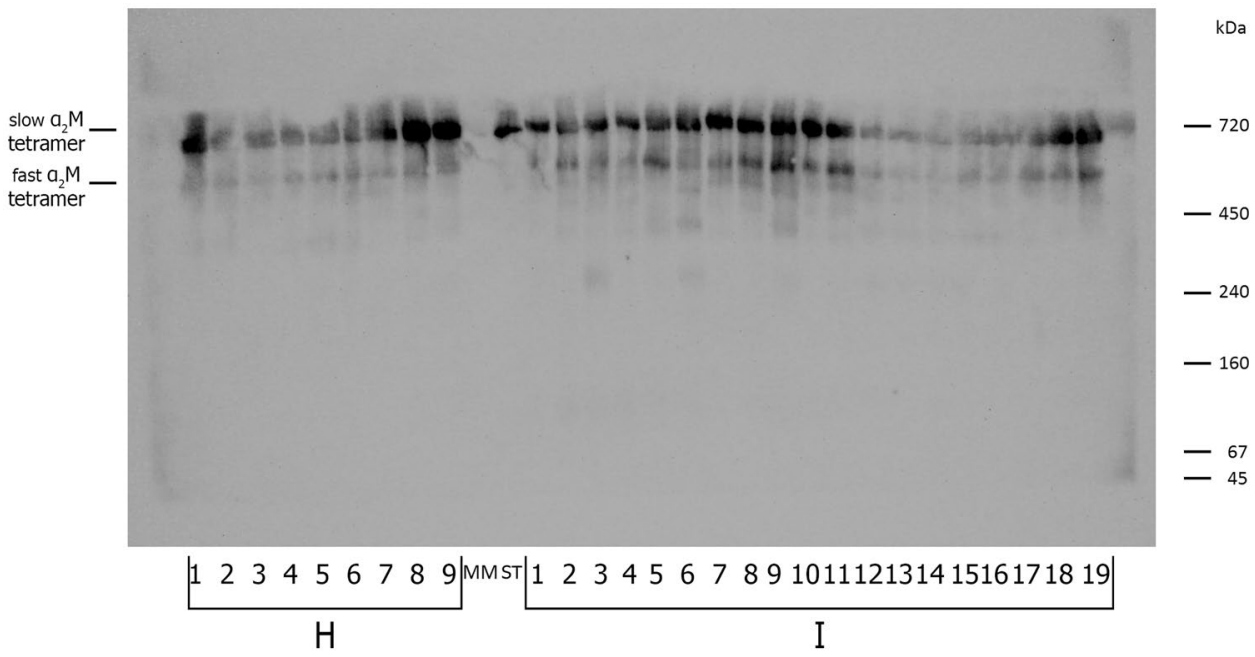

trapping of proteinases. Alpha-2-macroglobulin with bound proteinase(s) is cleared from the circulation by binding to low density lipoprotein receptor-related protein which can be found in many tissues, specifically on cells involved in endocytosis [32]. Oxidative conditions may cause dissociation of a tetramer into dimers which can non-covalently bind a number of molecules: cytokines, growth factors, and misfolded proteins. Native tetramer, proteinase-bound and dimer forms do not have the same sensitivity and specificity for ligands. Dimers exhibit increased binding of cytokines such as IL-2, IL-6 and tumor necrosis factor alpha.

Although the pregnancy zone protein (PZP) has high degree of sequence homology with alpha-2-macroglobulin [33], its concentration is much lower in plasma of healthy persons $(0.03 \mathrm{~g} / \mathrm{L})$ compared to alpha-2-macroglobulin (1.2-2.5 g/L, Table 1) [34]. An increase in PZP may occur in inflammatory diseases, and in HIV-1-positive persons, it was determined to be $125 \pm 65 \mu \mathrm{g} / \mathrm{mL}$, i.e., on average up to $0.2 \mathrm{~g} / \mathrm{L}$ [35]. Similar concentration was measured in patients with hepatitis B [36]. On the other hand, in the work of Tian et al. [37], immune suppression was reported in the early stage in Covid-19 patients accompanied by down-regulation of a number of proteins, including PZP-like alpha2-macroglobulin domain-containing protein 8 . Taking into account the order of the magnitude of the concentrations of alpha-2-macroglobulin and PZP, as well as the fact that patients included in this study were not pregnant and in the early phase of infection (not diagnosed before, C-reactive protein within reference range), it may be expected that the influence of the potential interference of PZP (if any) on results was not significant.

Alpha-2-macroglobulin binds $30-40 \%$ of plasma zinc with high affinity and zinc is essential for its function [22, 38, 39]. Cytokine IL-6 induces the expression of alpha-2-macroglobulin and reduces zinc availability [40]. It is plausible to hypothesize that inflammation, the predominant pathway in the immune response, and zinc status affect distribution of molecular forms of alpha-2-macroglobulin influencing its capacity to preferentially bind proteinases or cytokines, although not in a simple mathematical correlation.

An average relative abundance of albumin dimers in infected persons was lower compared to healthy individuals, suggesting an effective antioxidant activity in the circulation, which may also be related to increased levels of zinc (i.e., in 20 out of 60 individuals above the upper reference limit). Reduction of thiol groups and formation of disulfide bonds initiates albumin dimerization. A thiol group originating from Cys34 of human albumin is the major plasma antioxidant and important factor regulating the binding capacity for copper ions [41]. Formation of albumin dimers impairs binding and sequestration of free copper ions from the circulation. In the examined population of SARS-CoV-2 infected individuals, an increased concentration of zinc coincided with a reduced amount of albumin dimers.

\section{Conclusion}

Even in the early phase of Covid-19 infection, some proteins start to exhibit changes, either in their concentration (hemoglobin) or in the relative distribution of their molecular forms. Individuals infected with SARS-CoV-2 possess greater amounts of proteinase-bound tetramer alpha-2-macroglobulin and monomer albumin. This distribution correlates with the concentration of zinc ions within the reference range, but much higher zinc concentrations do not seem to be related to additional effects. Although we still have to wait for a firm confirmation of the involvement of zinc in beneficial defence mechanisms in patients with Covid-19, it seems that this ion may contribute to the existence of circulating protein forms which are the most optimal. 
Funding This work was supported by the Ministry of Education, Science and Technological Development of the Republic of Serbia (Grant no. 451-03-9/2021-14/200019).

Availability of data and material Electrophoretic data are available upon request.

\section{Declarations}

Conflict of interest There are no conflicts or competing interests to declare.

Ethical approval Approval no. 02-286/4.

Consent to participate Oral informed consent was obtained from participants regarding the use of their blood leftovers for the research purpose.

\section{References}

1. Carota G, Ronsisvalle S, Panarello F et al (2021) Role of iron chelation and protease inhibition of natural products on COVID19 infection. J Clin Med 10:2306

2. Zhu N, Zhang D, Wang W et al (2020) A novel coronavirus from patients with pneumonia in China, 2019. N Engl J Med 382:727-733

3. Kumar A, Kubota Y, Chernov M et al (2020) Potential role of zinc supplementation in prophylaxis and treatment of COVID-19. Med Hypotheses 144:109848

4. Yang M, Lai CL (2020) SARS-CoV-2 infection: can ferroptosis be a potential treatment target for multiple organ involvement? Cell Death Disc 6:130

5. Fooladi S, Matin S, Mahmoodpoor A (2020) Copper as a potential adjunct therapy for critically ill COVID-19 patients. Clin Nutr ESPEN 40:90-91

6. Domingo JL, Marques M (2021) The effects of some essential and toxic metals/metalloids in COVID-19: A review. Food Chem Toxicol 152:1121

7. Coverdale JPC, Barnett JP, Adamu AH et al (2019) A metalloproteomic analysis of interactions between plasma proteins and zinc: elevated fatty acid levels affect zinc distribution. Metallomics 11:1805-1819

8. Manley SA, Byrns S, Lyon AW et al (2009) Simultaneous Cu-, $\mathrm{Fe}-$, and $\mathrm{Zn}$-specific detection of metalloproteins contained in rabbit plasma by size-exclusion chromatography-inductively coupled plasma atomic emission spectroscopy. J Biol Inorg Chem 14:61

9. Aljadani H (2021) Impact of different dietary patterns and micronutrients on the immune system and COVID-19 infection. Curr Res Nutr Food Sci 9:127-138

10. Lv Y, Chen L, Liang et al (2021) Association between iron status and the risk of adverse outcomes in COVID-19. Clin Nutr ESPEN 40:3462-3469

11. Yağc1 S, Serin E, Acicbe Ö et al (2021) The relationship between serum erythropoietin, hepcidin, and haptoglobin levels with disease severity and other biochemical values in patients with COVID-19. Int J Lab Hematol 00:1-10. https://doi.org/10.1111/ ijlh.13479

12. Gammoh NZ, Rink L (2017) Zinc in Infection and Inflammation. Nutrients 9:624
13. Fukada T, Yamasaki S, Nishida K et al (2011) Zinc homeostasis and signaling in health and diseases. Zinc signaling. J Biol Inorg Chem 16:1123-1134

14. Mondal S, Manna S, Barik K et al (2020) Zinc and copper homeostasis is crucial to maintain the cellular health and their role in viral diseases including COVID-19. J Indian Chem Soc 97:1-8

15. Mayor-Ibarguren A, Busca-Arenzana C, Robles-Marhuenda A (2020) A hypothesis for the possible role of zinc in the immunological pathways related to COVID-19 infection. Front Immunol 11:1736

16. Vogel-González M, Talló-Parra M, Herrera-Fernández V et al (2021) Low zinc levels at admission associates with poor clinical outcomes in SARS-CoV-2 infection. Nutrients 13:562

17. Doboszewska U, Wlaź P, Nowak G et al (2020) Targeting zinc metalloenzymes in coronavirus disease 2019. Br J Pharmacol 177:4887-4898

18. Elham AS, Azam K, Azam J et al (2021) Serum vitamin D, calcium, and zinc levels in patients with COVID-19. Clin Nutr ESPEN 43:276e282

19. Heller RA, Sun Q, Hackler J et al (2021) Prediction of survival odds in COVID-19 by zinc, age and selenoprotein $\mathrm{P}$ as composite biomarker. Redox Biol 38:101764

20. Zeng H-L, Yang Q, Yuan P et al (2021) Associations of essential and toxic metals/metalloids in whole blood with both disease severity and mortality in patients with COVID-19. FASEB J 35:e21392

21. Dursun N, Aydogan S (1994) Comparative effects of calcium deficiency and supplements on the intestinal absorption of zinc in rats. Jpn J Physiol 44:157-166

22. King JC (2018) Yet again, serum zinc concentrations are unrelated to zinc intakes. J Nutr 148:1399-1401

23. Pincemail J, Cavalier E, Charlier C et al (2021) Oxidative stress status in COVID-19 patients hospitalized in intensive care unit for severe pneumonia. A pilot study. Antioxidants 10:257

24. Skalny AV, Timashev PS, Aschner M et al (2021) Serum zinc, copper, and other biometals are associated with COVID-19 severity markers. Metabolites 11:244

25. Hackler J, Heller RA, Sun Q et al (2021) Relation of serum copper status to survival in COVID-19. Nutrients 13:1898

26. Barrett AJ, Brown MA, Sayers CA (1979) The electrophoretically "slow" and "fast" forms of the $\alpha_{2}$-macroglobulin molecule. Biochem J 181:401-418

27. Yoshino S, Fujimoto K, Takada T et al (2019) Molecular form and concentration of serum $\alpha 2$-macroglobulin in diabetes. Sci Rep 9:12927

28. Sonnweber T, Boehm A, Sahanic S et al (2020) Persisting alterations of iron homeostasis in COVID19 are associated with nonresolving lung pathologies and poor patients' performance: a prospective observational cohort study. Respir Res 21:276

29. Biamonte F, Botta C, Mazzitelli M et al (2021) Combined lymphocyte/monocyte count, D-dimer and iron status predict COVID-19 course and outcome in a long-term care facility. J Transl Med 19:79

30. Ali N, Fariha KA, Islam F et al (2021) Assessment of the role of zinc in the prevention of COVID-19 infections and mortality: A retrospective study in the Asian and European population. J Med Virol 93:4326-4333

31. Cater JH, Wilson MR, Wyatt AR (2019) Alpha-2-macroglobulin, a hypochlorite-regulated chaperone and immune system modulator. Oxid Med Cell Longev 2019:5410657

32. Lillis AP, Van Duyn LB, Murphy-Ullrich JE et al (2008) LDL receptor-related protein 1: unique tissue-specific functions revealed by selective gene knockout studies. Physiol Rev 88:887-918 
33. Sand O, Folkersen J, Westergaard JG et al (1985) Characterization of human pregnancy zone protein. Comparison with human $\alpha_{2}$-macroglobulin. J Biol Chem 260:15723-15735

34. Catera JH, Kumitac JR, Abdallaha RZ et al (2019) Human pregnancy zone protein stabilizes misfolded proteins including preeclampsia- and Alzheimer's associated amyloid beta peptide. PNAS 116:6101-6110

35. Sarcione EJ, Biddle WC (2001) Elevated serum pregnancy zone protein levels in HIV-1-infected men. AIDS 15:2467-2469

36. Zarzur JA, Aldao M, Sileoni S et al (1989) Serum pregnancyassociated $\alpha 2$-glycoprotein levels in the evolution of hepatitis B virus infection. J Clin Lab Anal 3:73-77

37. Tian $\mathrm{W}$, Zhang N, Jin R et al (2020) Immune suppression in the early stage of COVID-19 disease. Nature Commun 11:5859

38. Mocchegiani E, Costarelli L, Giacconi R et al (2006) Zinc-binding proteins (metallothionein and alpha-2 macroglobulin) and immunosenescence. Exp Gerontol 41:1094-1107
39. Šunderić M, Mihailović N, Nedić O (2014) Protein molecular forms of the insulin-like growth factor binding protein 2 change with ageing. Exp Gerontol 58:154-158

40. Nuttall JR, Oteiza PI (2014) Zinc and the aging brain. Genes Nutr 9:379

41. Penezić AZ, Aćimović JM, Pavićević ID et al (2019) The interplay between copper(II), human serum albumin, fatty acids, and carbonylating agent interferes with Cys 34 thiol reactivity and copper binding. J Biol Inorg Chem 24:61-70

Publisher's Note Springer Nature remains neutral with regard to jurisdictional claims in published maps and institutional affiliations. 